\title{
INTEGRACIÓN DE LOS PRINCIPIOS DE LA ECONOMÍA SOCIAL Y SOLIDARIA EN EL DISEÑO SOSTENIBLE DE BIENES DE CONSUMO $^{1}$
}

\author{
INTEGRATION OF SOCIAL AND SOLIDARITY ECONOMY PRINCIPLES IN THE \\ SUSTAINABLE DESIGN OF CONSUMER GOODS
}

\section{INTEGRAÇÃO DOS PRINCÍPIOS DA ECONOMIA SOCIAL E SOLIDÁRIA NO DESENHO SUSTENTÁVEL DOS BENS DE CONSUMO}

\author{
Julia Galán Serrano² \\ Carmela Forés Tomás ${ }^{3}$ \\ Francisco Felip Miralles ${ }^{4}$
}

\begin{abstract}
Resumen
Desde un enfoque sostenible del diseño, es inevitable el cuestionamiento del actual sistema económico, así como de la propia práctica de la disciplina enfocada a la producción de objetos de consumo. En los últimos años, son muchos los sectores sociales que apuntan a la emergencia de un cambio en los modelos productivos y de consumo, y también a la necesidad de desarrollar nuevos modelos económicos que prioricen la supervivencia del ser humano. Este artículo establece un marco de reflexión sobre la integración de los principios de la economía social y solidaria en los procesos de diseño como portadores de una cultura de la solidaridad y de la sostenibilidad, con el fin de promover la generación de bienes de consumo destinados al mercado social. La estructura del artículo responde a una orientación teórica, puesto que tratamos de
\end{abstract}

DOi: https://doi.org/10.15359/eys.23-54.7

Fecha de recepción: 24-09-2018. Fechas de reenvíos: 08-10-2018, 20-11-2018. Aceptado el 26-11-2018. Publicado el 27-11-2018.

${ }^{1}$ Agradecimientos: El presente trabajo pertenece al proyecto de investigación Arte y diseño en la nueva sociedad digital (2016-2018), con código P1·1B2015-30 y financiado por la Universitat Jaume I, Castellón de la Plana, España.

2 Universitat Jaume I, Castellón de la Plana, España. Doctora en Bellas Artes. Catedrática de Universidad. Correo electrónico galan@uji.es

${ }^{3}$ Escola d'Art i Superior de Disseny de Castellón, Castellón de la Plana, España. Doctora en Diseño. Funcionaria interina del cuerpo de Profesorado de Artes Plásticas y Diseño. Correo electrónico cfores@easdcastello.org

${ }^{4}$ Universitat Jaume I, Castellón de la Plana, España. Doctor en Bellas Artes. Profesor contratado doctor. Correo electrónico ffelip@uji.es 
definir, en primer lugar, el concepto de economía social y solidaria, para después vincular este modelo transformador al concepto de diseño para el desarrollo humano sostenible. El principal objetivo es asentar unas bases conceptuales que nos permitan continuar con el estudio de herramientas y estrategias que promocionen el diseño como factor de culturización sostenible, de innovación y de bienestar social.

Palabras claves: Economía social y solidaria; mercado social; diseño sostenible; valores universales; consumo responsable.

\begin{abstract}
From a sustainable design approach, it is inevitable to question the current economic system and its practice focused on the production of consumer goods. In recent years, many social sectors have stated the urgent need to change production and consumption models and develop new economic models that would prioritize human survival. This paper establishes a framework to reflect on the integration of social and solidarity economy principles in the design processes as bearers of a solidarity and sustainability culture in order to promote the generation of consumer goods for the social market. The paper is structured with a theoretical approach since the authors first try to define the concept of social and solidarity economy and then link this transforming model to the concept of sustainable human development design. The paper's main objective is to establish conceptual bases that allow us to continue studying tools and strategies to promote the design as a factor of sustainable culture, innovation, and social welfare.
\end{abstract}

Keywords: Social and solidarity economy; social market; sustainable design; universal values; responsible consumption

\title{
Resumo
}

A partir de um enfoque sustentável do desenho, o questionamento do atual sistema econômico é inevitável, assim como a prática da disciplina voltada para a produção de objetos de consumo. Nos últimos anos, são muitos os setores sociais que apontam para a emergência de uma mudança nos modelos de produção e consumo, e também para a necessidade de se desenvolver novos modelos econômicos que priorizem a sobrevivência do ser humano. Este artigo estabelece um marco para a reflexão sobre a integração dos princípios da economia social e solidária nos processos de desenho como portadores de uma cultura de solidariedade e sustentabilidade, a fim de promover a geração de bens de 
consumo destinados ao mercado social. A estrutura do artigo responde a uma orientação teórica, uma vez que tentamos definir, em primeiro lugar, o conceito de economia social e solidária, e então vincular esse modelo transformador ao conceito de desenho para o desenvolvimento humano sustentável. O objetivo principal é estabelecer bases conceituais que nos permitam continuar com o estudo de ferramentas e estratégias que promovam o desenho como um fator de culturalização sustentável, da inovação e do bem-estar social.

Palavras-chave: Economia social e solidária; mercado social; desenho sustentável; valores universais; consumo responsável

\section{Introducción}

A partir de la segunda mitad del siglo XVIII, con la conquista de la Revolución Industrial y el dominio de los modelos científicos reduccionistas y mecanicistas, se consolida una nueva economía que propicia un modelo de bienestar social basado en la posesión y acumulación de capital. Las consecuencias negativas de la expansión de este sistema económico se hacen evidentes hoy y su globalización ha convertido a la especie humana en una patología parasitaria que avanza a ritmos incontrolados (Naredo, 2005).

La evolución del diseño industrial no ha quedado al margen de este modelo convirtiéndose en una disciplina basada en valores dirigidos principalmente al aumento y el estímulo de la demanda de mercado. La Organización Internacional de Diseño Industrial ICSID (International Council of Societies of Industrial Design), ahora denominada World Design Organization (WDO), define el diseño como un proceso estratégico de resolución de problemas que aporta nuevos valores y ventajas competitivas desde la esfera económica, social o ambiental (WDO, 2015). Actualmente el diseño se concibe como un valor de innovación para la empresa; sin embargo, en muchas ocasiones el peso del ámbito económico convierte el producto en un fin y no en un instrumento para mejorar el bienestar social y ambiental; aunque no siempre fue así. En sus inicios, la escuela de la Bauhaus defendió la democratización de los bienes en un intento de hacerlos llegar a la mayoría de la población. Finalmente, la subyugación al mercado hizo prosperar metodologías que abanderaban valores como la eficiencia, viabilidad, productividad, rentabilidad, eficacia o calidad; conceptos todos ellos vinculados a actividades puramente económicas. No fue hasta los años 60, con el nacimiento del movimiento ecologista, que se introdujo la preocupación ambiental en el proceso de diseño como valor a tener en cuenta hasta convertirse en una metodología propia como lo es el ecodiseño.

Sin embargo, y pese a que el crecimiento de la concientización social es cada vez más evidente, el deterioro del capital ambiental y social es cada vez mayor. En el ámbito del diseño, la

Julia Galán Serrano, Carmela Forés Tomás y Francisco Felip Miralles 
preocupación por la actual crisis sistémica se hace patente con el auge de algunas tendencias ecosociales -como es el caso del diseño abierto o el diseño para la innovación social- y también en el creciente discurso de profesionales (Bonsiepe, 2012; Chaves, 2002; Margolín, 2005) que reclaman la necesidad de integrar los principios éticos y sociales en los procesos de diseño. No obstante, todavía existe una gran dificultad para integrar valores intangibles en estos procesos.

No ocurre así en otras disciplinas, como la arquitectura, el urbanismo e incluso la economía, que si están encontrando nuevas vías para la integración de valores cualitativos en la toma de decisiones y valoración de los impactos sociales, culturales, económicos y éticos que generan.

Un ejemplo lo tenemos en la economía social y solidaria (de aquí en adelante ESS), que nos ofrece nuevos escenarios para el análisis de los procesos de integración de valores tangibles e intangibles que conforman una cultura alternativa al modelo de crecimiento ilimitado. El actual modelo económico se caracteriza por la acumulación de capital, la competencia, el control social y la sobreabundancia de bienes de consumo, lo cual conlleva a la destrucción del bienestar social, cultural y ambiental.

Hablar de sostenibilidad, desde el modelo económico capitalista, resulta casi imposible (Figura 1). Pero no ocurre así desde las economías transformadoras. La ESS entiende la economía como un medio y no como un fin, generando una esfera de valores que incluye, además del capital económico y material, otros valores inmateriales difícilmente cuantificables (valor social, ecológico, estético, emocional, simbólico, cognitivo, histórico, cultural, comunicativo, entre otros), los cuales configuran los principios éticos que guiarán todas las actividades económicas. Desde este modelo es posible hablar de desarrollo sostenible, puesto que su crecimiento no solo está ligado a la acumulación del capital económico, sino también al incremento del capital humano, social y ambiental.

En este artículo se analizan los valores y principios de la ESS y, también, las herramientas transformadoras que facilitan su integración en la práctica cotidiana económica. Su estudio permitirá conocer mejor cómo deben ser los bienes y servicios que derivan de su filosofía y, por tanto, cuáles son los valores que deben regir la práctica de un diseño transformador de bienes de consumo dirigidos al mercado social. 

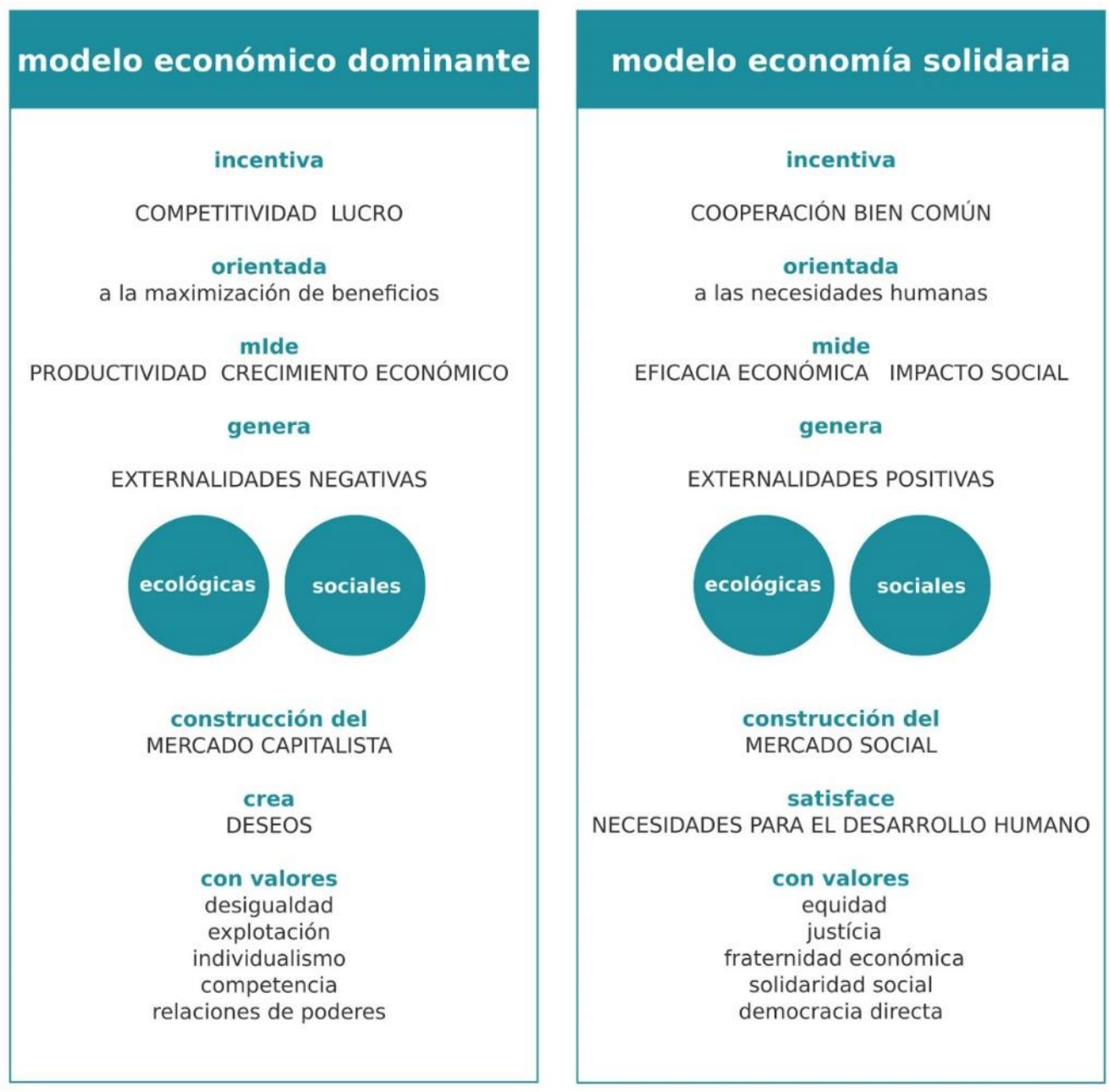

Figura 1. Esquema conceptual de los diferentes modelos económicos.

Fuente: adaptado del balance social de la Xarxa d'Economia Solidària (XES, 2013).

\section{Conceptos de la economía social y solidaria}

Definimos la economía social y solidaria como el "sistema socioeconómico, cultural y ambiental desarrollado de forma individual o colectiva a través de prácticas solidarias, participativas, humanistas y sin ánimo de lucro para el desarrollo integral del ser humano como fin de la economía" (Askunze, 2007, p. 108). La ESS se enmarca, junto con otras propuestas, dentro de las llamadas economías transformadoras.

Luis Razeto define la ESS con base en dos características: "su orientación fuertemente crítica y decididamente transformadora respecto a las grandes estructuras y los modos de organización y de acción que caracterizan la economía contemporánea" (Razeto, 2000, citado en Pérez de

Julia Galán Serrano, Carmela Forés Tomás y Francisco Felip Miralles 
Mendiguren et al., 2008, p. 10). No obstante, el autor enfatiza la importancia de un cambio cultural hacia modelos más austeros y simples que satisfagan las necesidades humanas desde actividades productivas, de consumo y distribución más responsables, próximas y sostenibles.

Esta cuestión es esencial para un nuevo diseño enfocado en el desarrollo humano sostenible puesto que, como actividad creativa y productiva, debe dirigir su mirada hacia una nueva cultura de la suficiencia desde la práctica responsable y la innovación social.

En esta línea se mueve el manifiesto de la Red de Economía Solidaria (firmado en 2002) que nombra como valor central de la economía a las personas y su trabajo. Así, los mercados pasan a estar al servicio de la sociedad y de su bienestar. El beneficio de una empresa no se limita a las aportaciones económicas, sino que también tiene en cuenta los beneficios ambientales y sociales. La ESS se propone como alternativa sostenible y viable, dentro de los límites biofísicos del planeta, al actual sistema económico, por medio de la transformación de las actividades económicas de producción (y, por tanto, también de diseño), consumo, distribución y financiación.

La Red de Redes de Economía Alternativa y Solidaria (de aquí en adelante REAS) sitúa entre las principales razones para apoyar la ESS y cambiar nuestros hábitos de consumo, la opulencia de unos pocos grupos y, por tanto, el aumento de la desigualdad social, la expoliación de los recursos naturales y el grave deterioro ambiental que ponen en peligro la continuidad de la vida humana en el planeta. Estas razones son suficientes para pensar que el consumo responsable y el desarrollo sostenible deben ser las referencias prioritarias para nuestro presente.

La ESS pretende incorporar, en las actividades económicas de producción, distribución, consumo y financiación, los valores universales que deberían guiar a la sociedad en su conjunto. Algunos elementos claves que nombra la Carta de Principios de la Economía Solidaria, elaborada por la REAS (2011), entre los que también está implicada la práctica del diseño de bienes y servicios, son: la reducción de la huella ecológica; la promoción de modelos de producción y consumo donde prime la austeridad, la suficiencia y la simplicidad; el apoyo de tecnología limpia; el uso racional de recursos; la diminución de la demanda energética, y el fomento de un consumo responsable, entre otros.

Pablo Guerra (2004) apunta hacia dos grandes objetivos en la ESS (a la que también llama socieconomía de la solidaridad): un objetivo práctico, que se vertebra en torno a valores solidarios en todas sus fases (producción, distribución, consumo y acumulación); y un objetivo teórico, que busca la construcción de una caja de herramientas que posibilite la aplicación de estas experiencias. Por tanto, la dirección que toma esta definición también iría, al igual que las anteriores, hacia la generación de un modelo transformador y alternativo a los modelos capitalistas predominantes.

102 
El autor define las características de esta economía desde las diferentes actividades económicas. Así, en el plano de la producción, contempla que la racionalidad económica viene dada por el factor trabajo, donde la solidaridad siempre está por encima del capital. Es el llamado factor C, el cual engloba la cooperación en el trabajo, el conocimiento compartido para aumentar la creatividad social, la adopción colectiva de decisiones para reducir la conflictividad, el desarrollo personal dentro de la empresa y, por último, el aumento de la participación para satisfacer las necesidades personales y sociales, las cuales aportan beneficios no monetarios. Por otra parte, en el plano de la distribución, los recursos y productos, además de intercambiarse a través del valor monetario, permiten establecer nuevas maneras de relacionarse económicamente que asimismo aumentan la integración y la participación social a través de la cooperación y la redistribución. Por último, en el proceso de consumo, la satisfacción de necesidades se realiza tomando conciencia del acto de consumir de manera responsable y solidaria. Algunas características que encontramos en este proceso son un mayor consumo comunitario que individual, la honestidad en la satisfacción de las necesidades, la proximidad en las relaciones entre ente productor y público consumidor, o la simplicidad y austeridad personal con el fin de frenar los graves problemas sociales y ecológicos globales.

En la misma línea del autor añadimos el plano del diseño, por considerarlo una actividad económica más. Así, y atendiendo las características mencionadas, se evidencia un cambio en la manera de entender la actividad, pues la demanda de necesidades ya no se realiza desde las esferas de mercado (como creadoras de deseos), sino que parten de las bases sociales (demanda de bienes útiles para el desarrollo humano). Numerosas tendencias en el diseño nos muestran estos cambios transformadores (diseño participativo, diseño para la innovación social y diseño colaborativo, entre otros) aunque no son muchas las que emanan de una visión integral de la cultura de la solidaridad y de la sostenibilidad.

Es importante remarcar el potencial transformador de la ESS para no caer en definiciones laxas que pretenden vaciarlo de significado, legitimando cualquier tipo de emprendimiento que pretenda contribuir al desarrollo social (Pérez de Mendiguren et al., 2008). Por ello, la práctica de un diseño transformador debe entenderse desde este enfoque crítico, así como también lo serán los principios y criterios que guiarán la integración de valores intangibles en el diseño de bienes y servicios dirigidos al mercado social.

\section{Valores y principios orientadores}

Hablar de economía social y solidaria es hablar desde un proyecto común e inclusivo que "consolida los valores universales que deben regir la sociedad y las relaciones entre toda la ciudadanía: equidad, justicia, fraternidad económica, solidaridad social y democracia directa" ( $\underline{\text { REAS }}$, 2011, p. 1). 
La Carta de Principios de la Economía Solidaria (REAS, 2011) toma, como principios de esta nueva racionalidad económica: la equidad, que defiende la distribución justa de recursos; la igualdad de derechos y de oportunidades; el derecho a la participación en la comunidad; un acceso transparente y libre a la información; la solidaridad con los colectivos más empobrecidos; el principio del trabajo desde su multidimensionalidad, para garantizar unas condiciones laborales dignas y justas que recoloquen las necesidades sociales en el centro, y que permitan desarrollar bienes y servicios sostenibles y responsables con el entorno; el principio de la sostenibilidad ambiental, que desde su multidimensionalidad profundiza en las relaciones que se establecen entre soberanía alimentaria, consumo consciente, decrecimiento, extracción y producción responsable, ambientalización educativa y estudio integral de la Naturaleza y, finalmente, la ordenación sostenible del territorio; el principio de la cooperación para trabajar desde relaciones colaborativas, íntimas y democráticas que promuevan un desarrollo local armónico y unas relaciones comerciales justas; el principio sin fines lucrativos desde una financiación ética y una rentabilidad integral de la empresa que promocione tanto los beneficios económicos como los ambientales y sociales; y por último, el principio de compromiso con el entorno que, partiendo desde la comunidad local, favorezca la generación de redes solidarias entre los diferentes movimientos sociales transformadores para la construcción de alternativas globales.

La REAS estipula los siguientes ejes transversales, que son la unión de los principios y las actuaciones de toda actividad ligada a la ESS:

La autonomía como principio de libertad y ejercicio de la corresponsabilidad; la autogestión como metodología que respeta, implica, educa, iguala las oportunidades y posibilita el empoderamiento; la cultura liberadora como base de pensamientos creativos, científicos y alternativos que nos ayudan a la investigación y el encuentro de nuevas maneras de convivir, producir, disfrutar, consumir y organizar la política y la economía al servicio de las personas; el desarrollo de las personas en todas sus dimensiones y capacidades: físicas, psíquicas, espirituales, estéticas, artísticas, sensibles, relacionales, entre otras, en armonía con la naturaleza, por encima de cualquier crecimiento desequilibrado económico, financiero, bélico, consumista, transgénico y anómalo como el que se está propugnando con el nombre de un desarrollo "ficticio»; la compenetración con la Naturaleza; la solidaridad humana y económica como principio de nuestras relaciones locales, nacionales e internacionales. (REAS, 2011, p. 1)

Como hemos comentado anteriormente, la ESS debe entenderse desde un enfoque multisistémico que abarca -además de la esfera económica- las esferas social, cultural y ambiental. La Figura 2 muestra una visión global de la complejidad del sistema, y ayuda a entender mejor las interacciones y relaciones que se producen en este nuevo paradigma. 


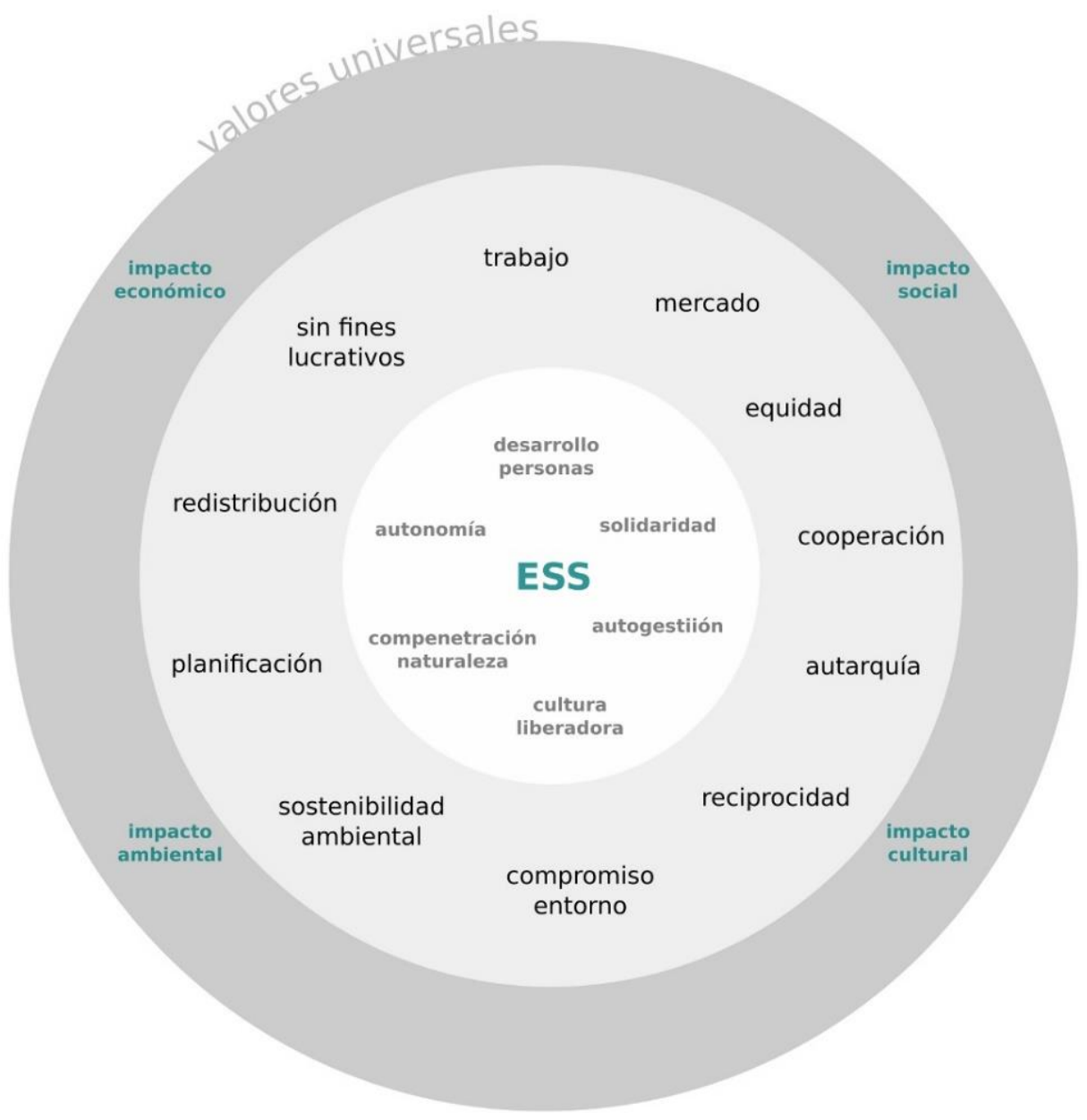

Figura 2. Enfoque multisistémico de la economía social y solidaria. Fuente: Forés (2016)

En suma, la esencia del movimiento de la ESS es la transformación social, la coherencia con sus valores y principios, y la racionalidad económica basada en la solidaridad, la sostenibilidad y unas relaciones horizontales y cooperativas que persiguen la satisfacción de necesidades y el desarrollo humano, individual y comunitario, en vez de la maximización del beneficio económico. Así pues, los bienes y servicios de la ESS están centrados en su valor de uso, es decir, son socialmente útiles para el desarrollo humano sostenible y, por tanto, será necesaria la práctica de un diseño, entendido como proceso creativo y transmisor de valores culturales, con una visión crítica y multisistémica, mediante la construcción de herramientas que facilitan la internalización de los valores éticos y de una cultura de la sostenibilidad y la solidaridad. La economía solidaria cuenta con herramientas enfocadas en conocer el grado de integración de los principios y valores en los procesos económicos. De entre ellas destacamos el mercado social, por la vinculación directa que tiene con el diseño de bienes de consumo. 


\section{El mercado social como herramienta de transformación social}

La economía solidaria reflexiona sobre todos aquellos aspectos que, de alguna manera, sostienen el funcionamiento económico de la comunidad, desde la producción de bienes y servicios hasta el consumo, pasando por las relaciones que se establecen entre personas y organizaciones. El componente ideológico sobre qué, cómo, para qué y para quién producir afecta directamente la vida colectiva y, por lo tanto, debe estar presente en las prácticas económicas de manera clara y transparente. Por ello, desde el ideario de la ESS, se fomentan los bienes y servicios destinados al mercado social con criterios democráticos, solidarios y sostenibles.

Situándonos en la práctica del diseño transformador, la cuestión es cómo se integran estos criterios en la configuración de los productos. Como se ha comentado antes, la ESS cuenta con herramientas enfocadas a analizar el grado de integración de los principios y valores en la práctica de las entidades, pero aún no dispone de herramientas que puedan permitir el análisis, evaluación o incluso la toma de decisiones para desarrollar los productos que ofrecen. Algunas de las herramientas que desarrolla la ESS, además del mercado social, y que tienen potencial para integrar, a corto o largo plazo, criterios evaluativos enfocados en los productos son: los balances sociales y las certificaciones de garantía ecosocial:

- Los balances sociales son herramientas de autodiagnóstico para conocer el nivel de integración de los principios y valores de la ESS en las organizaciones. Es interesante su análisis por los criterios de evaluación que utiliza, aunque al día de hoy apenas cuenta con indicadores de medida para los productos que desarrollan las empresas.

- Las certificaciones de garantía ecosocial, por otra parte, son procedimientos para garantizar que un producto, servicio o empresa está en conformidad con ciertas normas, criterios o estándares. Los sellos o etiquetas son instrumentos de certificación que tienen como objetivo principal aportar transparencia al público consumidor, por tanto, deben mostrar desde qué criterios éticos, sociales y ambientales se ha configurado un producto o servicio. Aunque la ESS apenas cuenta con sellos propios, hay un interés creciente, sobre todo en cuanto a la escalabilidad de los productos del mercado social y el fomento del consumo responsable y consciente entre la sociedad.

\subsection{Definiendo el mercado social}

La REAS define el mercado social como "una red de producción, distribución y consumo de bienes y servicios y aprendizajes comunes, que funciona con criterios éticos, democráticos, ecológicos y solidarios, en un determinado territorio, constituida tanto por las empresas y entidades de la economía solidaria y social como por consumidores/as individuales y colectivos" (Ortega, 2000, p. 1). La XES (Xarxa d’Economia Solidària) considera el mercado social como una herramienta 
transformadora necesaria para articular modelos cooperativos entre los diferentes agentes del circuito económico, como muestra la Figura 3.

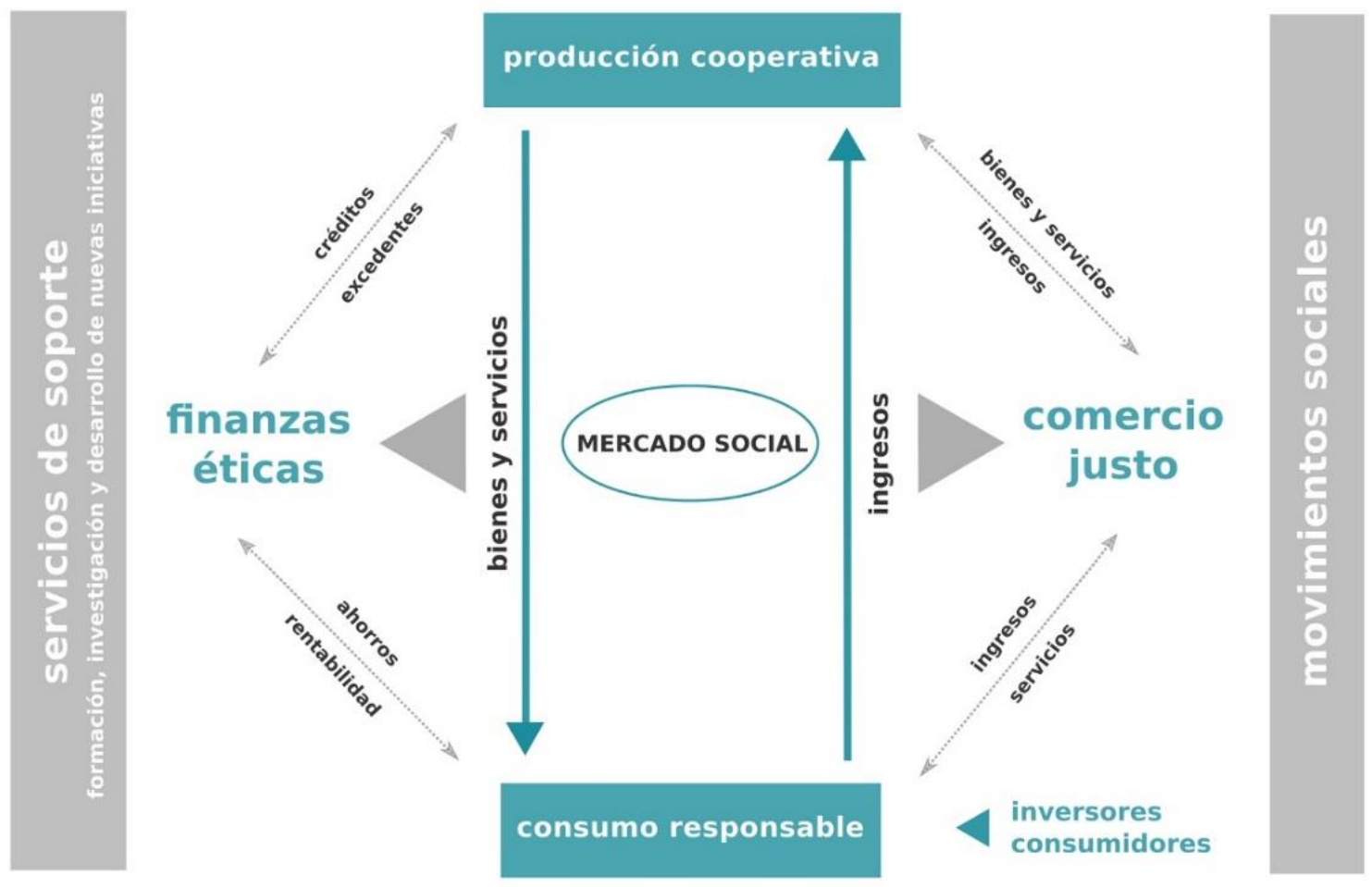

Figura 3. Nodos y flujo del mercado social. Fuente: adaptado de Jordi García Jané en Crespo y Sabín (2014, p. 99).

La cooperación entre las organizaciones es una práctica necesaria y la interrelación es una de las condiciones más importantes, así lo subrayan miembros del Proyecto Democracia Económica (2009) cuando se refieren a las diferentes realidades económicas alternativas de cada uno de los tres mercados conocidos: bienes y servicios, capitales y trabajo.

Crespo y Sabín (2014) señalan cuatro elementos mínimos que identifican un mercado social: una base transformadora de las condiciones de mercado, los agentes económicos conscientes (público consumidor y empresas), un proceso democrático en la organización del mercado (transparencia y participación) y, por último, la combinación de herramientas de visibilización, comercialización y de acceso a un consumo responsable. Para que estos elementos sean reconocidos socialmente, el mercado social debe fomentar la creación de herramientas que faciliten su dinamización y escalabilidad, así como generar las estrategias necesarias para difundir los principios y valores de la ESS de manera que aumente la confianza entre los consumidores y las consumidoras. 


\subsection{Servicios y bienes económicos en el mercado social}

Los bienes y servicios económicos se regulan con base en la disponibilidad de recursos; por lo tanto, en un mundo finito, las sociedades no disponen de suficientes recursos para satisfacer todas sus necesidades, y por ello tienen que elegir qué bienes se producen y cuáles no, así como definir también qué necesidades son prioritarias. De esta forma nos encontramos ante tres grandes cuestiones en toda economía: qué, cómo y para quién.

A la hora de preguntar acerca de qué bienes y servicios se han de producir y en qué cantidades, se plantea el problema de cómo y en qué se utilizan los recursos disponibles. La economía solidaria promueve la creación de herramientas capaces de detectar las necesidades sociales e individuales y, de esta manera, producir productos socialmente útiles que permitan un desarrollo humano sostenible. También reflexiona sobre cómo aumentar la participación social para determinar qué bienes y servicios son más prioritarios para el bien común. No son los agentes económicos unilateralmente los que deciden en función de su beneficio propio, sino la sociedad en su conjunto para asegurar las necesidades básicas, y también diferenciadas, de toda la población.

Para responder a la pregunta de cómo deben ser producidos, hay que anteponer criterios de producción local, solidaria y sostenibilidad por encima de criterios económicos.

Por último, sobre para quién o de qué manera se distribuirán, la economía solidaria defiende una distribución justa, equitativa y racional de la riqueza, los recursos y las capacidades, y también un consumo responsable basado en la solidaridad. De este modo, la libre elección -o el poder adquisitivo- para obtener un bien o servicio por unos pocos individuos en el mercado, no puede suponer la reducción de libertad de otros. Los bienes económicos no son meramente cosas para ser consumidas, sino satisfactores de necesidades para el desarrollo humano. En la distribución de los bienes se debería evitar el lucro excesivo de una minoría a costa de la pobreza extrema de la mayoría.

Teniendo en cuenta estas cuestiones, el diseño dirigido al mercado social debe ser un instrumento transformador que potencie un nuevo sistema de necesidades para un desarrollo humano sostenible y con capacidad para generar satisfactores que estén al servicio del bienestar colectivo (Figura 4). El ámbito del diseño tiene que abandonar la idea de un mundo lleno y embarcarse en el desarrollo de productos que potencian aquellas capacidades humanas que dotan a las personas de una buena vida, autosuficiente y en equilibrio con el entorno. 


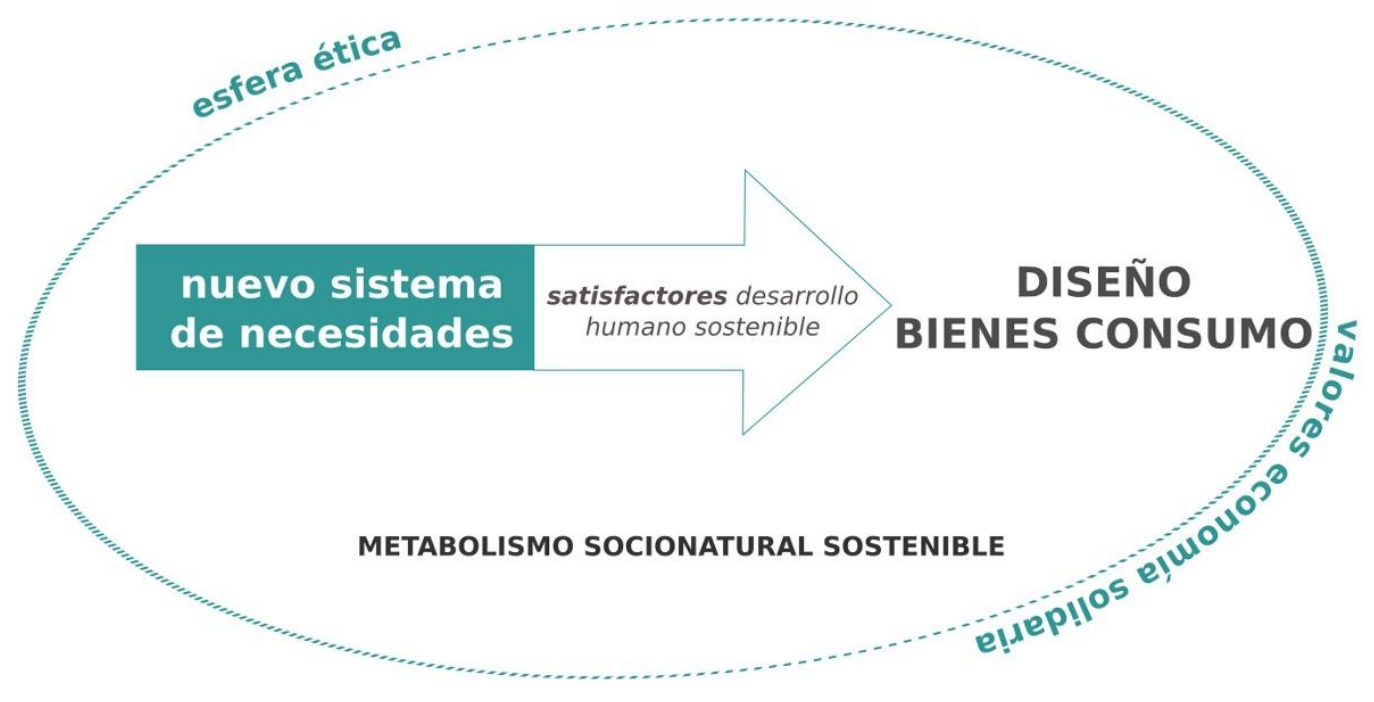

Figura 4: Diseño de bienes y servicios para un desarrollo humano sostenible y solidario. Fuente: Forés (2016)

\section{El diseño transformador en la economía social y solidaria}

La nueva racionalidad económica solidaria posiciona el valor de uso y simbólico de los bienes y servicios por encima de los valores de cambio y de la lógica del mercado. El diseño de bienes y servicios dirigidos al mercado social no queda al margen de estos valores, y así su práctica debe entender el consumo como un proceso social de construcción de una nueva identidad colectiva ligada al desarrollo sostenible y a una mejora de la calidad de vida, alejada de la cultura de la materialidad característica de la sociedad de consumo. Los objetos diseñados han de tener en cuenta esta lógica de la significación atendiendo las informaciones -valores semánticos en muchas ocasiones difíciles de visibilizar- que transmiten al grupo receptor.

En este marco podemos entender el diseño desde dos vertientes. Una más creativa e innovadora, desde donde generar bienes y servicios que fomentan nuevos modelos de consumo orientados desde una cultura de la solidaridad y de la sostenibilidad, y también, potenciar aquellos satisfactores que desarrollan las capacidades de las personas y de las comunidades, a fin de mejorar su calidad de vida. Y otra más metódica, como proceso proyectual, desde donde tomar decisiones de configuración de los productos teniendo en cuenta el ciclo de vida y, por tanto, los impactos, con una visión sistémica (ambiental, social, cultural y económica), a lo largo de todas las actividades económicas (producción, distribución, comercialización y consumo). 
Así, Razeto (1993) nos aporta algunas consideraciones e implicancias que pueden tener la aplicación de la cultura de la solidaridad a lo largo de las actividades económicas de una economía a escala: en el proceso productivo, en la distribución y en el proceso de consumo.

En el proceso productivo, fomentar una producción descentralizada y con mayor control por parte de los sectores involucrados para reducir el gasto energético. También implica la demanda de recursos (materiales y energéticos) renovables y locales para utilizar procesos de menor intensidad mecánica y química. Todo ello favorece la mejora de la gestión final de residuos. En el ámbito del diseño de productos, implica la selección de métodos productivos de menor intensidad energética y una preferencia por el uso de materiales locales, renovables y reciclables.

En la distribución, la localización reduce el gasto energético en el transporte de bienes; además, de esta manera se fomenta el uso de recursos locales y se recortan distancias entre sector productor y grupo consumidor. En el ámbito del diseño, la distribución a escala supone la creación de productos de proximidad, lo que implica la selección de sistemas productivos y de materiales cuanto más cercanos mejor, de manera que se consigue reducir la huella ecológica. Actualmente, el diseño de nuevos sistemas de distribución más sostenibles abre las puertas para la innovación social $y$, por tanto, a nuevos escenarios desde donde el diseño experto pueda aportar sus conocimientos.

Por último, en el proceso de consumo se deben anteponer los bienes comunes sobre los individuales, y asociar íntimamente bienestar personal con bienestar comunitario como síntoma de calidad de vida. Esta participación fomenta la visión de proyecto común y, por tanto, de corresponsabilidad. En este punto, resulta conveniente fomentar cierta austeridad en el consumo de algunos productos y un cambio en los patrones de consumo actuales, más vinculados a la posesión material. Para ello es imprescindible reflexionar sobre la satisfacción de necesidades dirigidas hacia un desarrollo humano sostenible alejado de las prácticas consumistas actuales. Otras estrategias transformadoras a promover serían el uso eficiente y perdurable de los bienes, para evitar que sean sustituidos por otros rápidamente, e impulsar el consumo de bienes comunitarios para mejorar la utilidad potencial del producto y reducir el gasto energético innecesario.

Con base en Razeto (1993), se puede definir el buen diseño como aquel diseño perfeccionado, más humano, saludable y ecológico, lo cual implicaría, entre otras cosas, la preferencia por el diseño de bienes públicos o colectivos por encima de los privados; el aumento de los bienes relacionales, culturales o espirituales que favorezcan el desarrollo de las capacidades humanas de manera sostenible y, para evitar la sustitución prematura de productos, la restitución del valor simbólico por encima del valor de signo (moda, estatus, etc.) y de mercado.

En la misma línea de reflexiones convergen algunos de los criterios que se establecen desde el Mercado de Economía Social de Madrid (MESM, 2014) y que determinan cómo deben ser los 110

Julia Galán Serrano, Carmela Forés Tomás y Francisco Felip Miralles

Revista Economía y Sociedad by Universidad Nacional is licensed under a CreativeCommons Reconocimiento-NoComercial- 
buenos productos dirigidos al mercado social: productos naturales, es decir, que no sufran alteraciones artificiales o contaminaciones químicas; que sean ecológicos; que acompañen al ciclo natural local en la distribución, venta y consumo y minimicen el uso de materiales; productos sanos y transparentes con las personas y con el entorno; que estén pensados, diseñados, distribuidos y comercializados a pequeña escala, preferentemente de manera local y con un vínculo estrecho entre los diferentes actores económicos; productos artesanos, fabricados con una contribución manual directa del artesano o artesana y con el uso de materias primas procedentes de recursos sostenibles; productos de calidad, que garanticen la transparencia desde la producción hasta su consumo y que tengan en cuenta la rentabilidad integral (económica, social y ambiental); que minimicen la huella ecológica al considerar el ciclo de vida del producto y la incorporación de estrategias para reducir el impacto ambiental, como, por ejemplo, en el uso preferente de materiales renovables, la eficiencia energética en la producción o mejoras en la gestión final de residuos; que se potencie la producción libre, los bienes del procomún y la cultura libre; preferencia por los productos de comercio justo que garanticen la libertad de comercio en igualdad de condiciones, seguridad en el ámbito laboral y un precio justo para cada agente económico involucrado, especialmente aquellos que provienen de países empobrecidos, y, por último, preferencia por aquellos productos que tengan en cuenta la inserción laboral de las personas en riesgo de exclusión.

Finalmente, conviene reseñar que el propio contexto sociohistórico marca las formas de pensar lo social y, por tanto, define la lógica en las actividades económicas. Por ello, con más motivo, se debe apostar por implicar a todos los agentes económicos (incluyendo profesionales del diseño) en este caminar hacia un mundo mejor y asumir la responsabilidad social en un proyecto común. En un mundo conectado a tiempo real, la praxis del diseño puede impactar masivamente de manera positiva o negativa en numerosos ámbitos de la sociedad (ambiental, cultural, salud, entre otros). El lenguaje comunicativo (simbolismo y significación) empleado en el diseño de los productos tiene potencial para transformar determinados comportamientos, por lo que la práctica del diseño, dirigida a la reproducción de la vida, debe apoyarse necesariamente en una cultura de la sostenibilidad y de la solidaridad.

\section{Conclusiones}

La economía social y solidaria se constituye como un nuevo paradigma para lograr un desarrollo humano sostenible. El mercado social, como espacio de intercambio de satisfactores de necesidades, demanda la construcción de un nuevo sistema de necesidades de acuerdo con el desarrollo sostenible de las capacidades humanas para la mejora de oportunidades en armonía con los sistemas naturales. La transformación de la actual cultura de la opulencia solo será posible desde un nuevo sistema de necesidades instrumentales, históricas y, por tanto, susceptibles de modificación, que cambian los hábitos hacia el acto de consumir desde un metabolismo socionatural sostenible. Dentro de este metabolismo, el mercado social demanda la producción de bienes y servicios responsables y sostenibles; también, la generación de herramientas

Julia Galán Serrano, Carmela Forés Tomás y Francisco Felip Miralles 
participativas que localicen las necesidades colectivas con la finalidad de priorizar aquellos productos socialmente útiles. En este marco, el diseño tiene que abandonar la idea de un «mundo lleno" y pasar a potenciar aquellas capacidades humanas que dotan a las personas de una buena vida, autosuficiente y sostenible con el entorno natural. Diseñar para el desarrollo humano sostenible implica la práctica de un diseño perfeccionado, más humano, saludable y ecológico.

La economía solidaria utiliza herramientas evaluativas, analíticas y exploratorias para poner en práctica y revisar el cumplimiento de su filosofía, como son los balances sociales o las etiquetas de garantía ecosocial, si bien aún no cuenta con indicadores que, de alguna manera, midan la internalización de sus valores en los productos ofrecidos en el mercado social. El desarrollo de bienes y servicios desde criterios democráticos, solidarios y sostenibles implica la integración de valores cualitativos en su diseño y, también, la generación de criterios específicos que puedan certificar los atributos de confianza a nivel ambiental, social y ético. La promoción del diseño como factor de culturización sostenible, de innovación social y de bienestar, debe ser una herramienta más en la búsqueda de estrategias hacia la transformación social. En este proceso, el diseño también debe posicionarse como un medio y no como un fin, centrarse en el desarrollo de las personas y no en el mercado e integrar, entre sus estrategias, los principios y valores de las economías transformadoras.

La economía social y solidaria nos ofrece un marco transformador para el diseño desde donde reflexionar sobre los procesos de integración de los valores universales que promueve. Los objetivos de las diferentes actividades económicas de producción, distribución y consumo, incluyendo el diseño, evidencian que otras maneras de hacer las cosas son posibles. Se encuentran ejemplos en los bienes y servicios dirigidos al mercado social, que se configuran para ser socialmente útiles para el desarrollo humano sostenible. Así, podemos concluir que la práctica de un diseño transformador desde la economía social y solidaria -entendida como actividad económica, pero también como sistema de signos y, por lo tanto, transmisor de valores culturales- debe realizarse desde una visión crítica y multisistémica, mediante la construcción de herramientas que faciliten la internalización de los valores éticos y una cultura de la sostenibilidad y la solidaridad. 


\section{Referencias}

Askunze, C. (2007). Economía solidaria. En G. Celorio y M. A. López (Coords.), Diccionario de educación para el desarrollo (pp. 107-112). Bilbao, España: Hegoa. Recuperado de http://publicaciones.hegoa.ehu.es/uploads/pdfs/62/Diccionario de Educacion par a el Desarrollo.pdf?1488539200

Bonsiepe, G. (2012). Diseño y crisis. Valencia, España: Campgràfic. Recuperado de https://www.amazon.es/Dise\%C3\%B1o-Y-Crisis-Gui-Bonsiepe/dp/8496657280

Chaves, N. (2002). El oficio de diseñar: Propuestas a la conciencia crítica de los que comienzan. Barcelona, España: Gustavo Gili. Recuperado de https://www.casadellibro.com/libroel-oficio-de-disenar-propuestas-a-la-conciencia-critica-de-los-q-uecomienzan/9788425218408/746958

Crespo, B. y Sabín, F. (2014). Los mercados sociales. La economía solidaria en acción transformadora. Documentación social, (174), 95-116. Recuperado de https://www.economiasolidaria.org/sites/default/files/Los\%20mercados\%20sociale $\underline{\text { s.pdf }}$

Forés, C. (2016). Dissenyar per a un desenvolupament humà sostenible i solidari. Proposta de principis i criteris per a l'acció (Tesis Doctoral). Universitat Jaume I, Castellón, España. doi: http://dx.doi.org/10.6035/14031.2016.87584

Guerra, P. (2004). Economía de la Solidaridad. Una introducción a sus diversas manifestaciones teóricas. Recuperado de http://tacuru.ourproject.org/documentos/guerra.pdf

Margolin, V. (2005). Las políticas de lo artificial: Ensayos y estudios sobre diseño. México D.F., México: Designio. Recuperado de https://di3prod.files.wordpress.com/2011/06/margolin-victor-las-politicas-de-loartificial1.pdf

Mercado de Economía Social de Madrid. (2014). Valores y compromisos del mercado social. Recuperado https://madrid.mercadosocial.net/docs/Carta_PrincipiosMES_03 2014.pdf

Naredo, J. M. (2005). El metabolismo económico y sus perspectivas. En J. M. Naredo y L. Gutiérrez (Eds.), La incidencia de la especie humana sobre la faz de la tierra (1955-2005) (pp. 183-216). Granada, España: Universidad de Granada y Fundación César Manrique. 
Pérez de Mendiguren, J. C., Etxezarreta, E. y Guridi, L. (marzo de 2008). ¿De qué hablamos cuando hablamos de economía social y solidaria? Concepto y nociones afines. En Bienestar y Democracia Económica Global. Conferencia llevada a cabo en las XI Jornadas de Economía Crítica, Bilbao, España. Recuperado de http://www.caritasburgos.es/documentos/documentacion/12Econom\%C3\%ADa\%20social\%20y\%20solidaria.pdf

Ortega, S. (noviembre, 2000). Mercado social. Comunicación presentada en el Seminario Construyendo un Mercado Alternativo de Economía Solidaria, Bilbao. Recuperado de https://www.economiasolidaria.org/sites/default/files/mercado social.pdf

Proyecto Democracia Económica. (2009). El mercat social: és possible articular una xarxa alternativa? En A. Comín y L. Gervasoni (Coords.), Democràcia econòmica. Vers una alternativa al capitalisme (pp. 401-409). Barcelona, España: Projecte Democràcia Econòmica.

Razeto, L. (1993). Los caminos de la economía de solidaridad. Santiago de Chile, Chile: Ediciones Vivarium. Recuperado de https://lacoperacha.org.mx/documentos/coperachaeconomia-solidaria-razeto.pdf

Red de Redes de Economía Alternativa y Solidaria. (2011). Carta de Principios de la economía solidaria. Recuperado de http://deveconomiasolidaria.devtopia.coop/sites/default/files/pages attachments/CARTA EC ONOMIA SOLIDARIA REAS.pdf

World Design Organization. (2015). Definition of Industrial Design. Recuperado de http://wdo.org/about/definition/

Xarxa d'Economia Solidària. (2013). Balanç social de la xarxa d'economia solidària. Recuperado de http://sostenibilitatbcn.cat/attachments/article/755/Presentacio\%20BSXES 20122013.pdf 